\title{
Integrated water vapor from IGS ground-based GPS observations: initial results from a global 5-min data set
}

\author{
S. Heise, G. Dick, G. Gendt, T. Schmidt, and J. Wickert \\ Helmhotz Centre Potsdam, GFZ German Research Centre for Geosciences, Department 1 Geodesy and Remote Sensing, \\ Telegrafenberg, 14473 Potsdam, Germany
}

Received: 9 January 2009 - Revised: 13 May 2009 - Accepted: 13 July 2009 - Published: 16 July 2009

\begin{abstract}
Ground based GPS zenith path delay (ZPD) measurements are well established as a powerful tool for integrated water vapor (IWV) observation. The International GNSS Service (IGS) provides ZPD data of currently more than 300 globally distributed GPS stations. To derive IWV from these data, meteorological information (ground pressure and mean temperature above the station) are needed. Only a limited number of IGS stations is equipped with meteorological ground sensors up to now. Thus, meteorological data for IWV conversion are usually derived from nearby ground meteorological observations (ground pressure) and meteorological analyses (mean temperature). In this paper we demonstrate for the first time the applicability of ground pressure data from ECMWF meteorological analysis fields in this context. Beside simplified data handling (no single station data and quality control) this approach allows for IWV derivation if nearby meteorological stations are not available. Using ECMWF ground pressure and mean temperature data the new IGS 5-min ZPD data set has been converted to IWV for the first time. We present initial results from selected stations with ground meteorological sensors including pressure and temperature comparisons between ECMWF and local measurements. The GPS IWV is generally validated by comparison with ECMWF IWV. The ECMWF derived station meteorological data are compared with local measurements at all accordingly equipped stations. Based on this comparison, the mean error (in terms of standard deviation) introduced by time interpolation of the 6-hourly ECMWF data is estimated below $0.2 \mathrm{~mm}$ IWV.
\end{abstract}

Keywords. Atmospheric composition and structure (Instruments and techniques) - Meteorology and atmospheric dynamics (Instruments and techniques; General or miscellaneous)

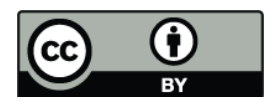

Correspondence to: S. Heise (stefan.heise@gfz-potsdam.de)

\section{Introduction}

Water vapor plays a key role in the Earth's atmosphere system. It significantly influences the hydrological cycle (water transport, clouds, precipitation) and transports large amounts of latent heat energy. Due to its radiational properties and global appearance water vapor represents the most important greenhouse gas. Thus, precise knowledge of spatial and temporal water vapor distribution is important in meteorology for both, numerical weather prediction and climatological studies. In particular global long-term water vapor data sets are essential for understanding and modeling of the climate system. In this context especially quantification of water vapor feedback in climate change is of particular importance (e.g., Hall and Manabe, 1999). Considering the high temporal and spacial variability of water vapor, the conventional global observing systems (i.e. radiosondes and satellite observations) are not suited to provide sufficient information. Furthermore, radiosonde data suffer from deficient long-term stability related with changes in instrumentation, calibration and data analysis (e.g., Zhai and Eskridge, 1996). Thus, additional water vapor data from new observation techniques are highly desirable to achieve adequate observation coverage, accuracy and long-term stability.

Crossing the atmosphere, Global Positioning System (GPS) signals experience a propagation delay depending on constitution of the ionosphere (electron density) and neutral atmosphere (pressure, temperature, water vapor). The neutral atmosphere related zenith path delay (ZPD) above each GPS ground station is a standard product of routine GPS data processing and the humidity induced part of ZPD provides a valuable source of vertically integrated water vapor (IWV) information (e.g., Bevis et al., 1992; Rocken et al., 1993; Bevis et al., 1994; Businger et al., 1996). The GPSbased IWV observation technique is characterized by several advantages in comparison to the traditional observing systems: independence on sensor calibrations and therefore long-term stability, all-weather capability, high accuracy and

Published by Copernicus Publications on behalf of the European Geosciences Union. 
low cost. Several validation studies show well agreement between IWV from GPS and other observing systems like radiometers or radiosondes (e.g., Rocken et al., 1993; Tregoning et al., 1998; Deblonde et al., 2005; Wang et al., 2007). Thus, GPS IWV is used in several applications like numerical weather prediction (e.g., Gendt et al., 2004; Gutman et al., 2004; Vedel et al., 2004; Guerova et al., 2006), validation of IWV results from other sensors (e.g., Li et al., 2003; Van Baelen et al., 2005) and first climatological investigations (e.g., Gradinarsky et al., 2002; Nilsson and Elgered, 2008).

Based on its global network observations (currently more than 300 stations), the International GNSS (Global Navigation Satellite System) Service (IGS, Beutler et al., 1999) provides 2-hourly measurements of ZPD from February 1997 until the end of 2006 and a new 5-min ZPD data set starting from October 2000. While there are numerous investigations using GPS IWV on a regional scale, only one study describing a long-term IWV data set from the global 2-hourly IGS ZPD product is published up to now (Wang et al., 2007). In this paper we present initial results of IWV derivation from the 5-min IGS ZPD data set. Except for the slightly shorter time interval this new IGS product is superior to the 2-hourly data set in several aspects including long-term stability, accuracy and number of stations (Byun et al., 2005). Derivation of IWV from ZPD data requires pressure and temperature information at the station (Bevis et al., 1992). Numerous IGS stations are not equipped with meteorological sensors. Thus, meteorological data for IWV conversion have to be interpolated from nearby meteorological stations or analysis fields of numerical weather prediction (NWP) models. While NWP analysis fields are widely used to derive the temperature information (e.g., Wang et al., 2005), their accuracy concerning ground pressure data is under discussion (e.g., Hagemann et al., 2003; Nilsson and Elgered, 2008). Hence, in most studies pressure data are interpolated from nearby meteorological stations (e.g., Hagemann et al., 2003; Wang et al., 2007). Nilsson and Elgered (2008) applied pressure estimates from a regional model of the Swedish Meteorological and Hydrological Institute (SMHI). In this paper we demonstrate for the first time the applicability of ground pressure data from global meteorological analysis fields from the European Centre for Medium-Range Weather Forecasts (ECMWF) in this context. Beside simplified data handling (no single station data and quality control) this approach allows for IWV derivation if nearby meteorological stations are not available. We compare the ECMWF-derived station meteorological data with local measurements at all accordingly equipped IGS stations. This allows for accuracy estimation also regarding temporal interpolation between the 6-hourly ECMWF analysis fields. The GPS IWV is generally validated by comparison with ECMWF IWV at analysis times.

\section{Data analysis}

The common analysis procedure to derive IWV from ZPD is described in several publications (e.g., Bevis et al., 1992, 1994; Hagemann et al., 2003; Wang et al., 2007). Thus, we give only a brief overview here. As shown in Eq. (1), ZPD consists of the zenith hydrostatic delay (ZHD) and the zenith wet delay (ZWD), which yields the water vapor information.

$\mathrm{ZPD}=\mathrm{ZHD}+\mathrm{ZWD}$

Assuming hydrostatic equilibrium, the ZHD can be calculated as a function of the surface pressure $P_{S}$ (at GPS antenna height). Here we follow the IERS Conventions (2003) with the formula of Saastamoinen (1972) as given by Davis et al. (1985)

$\mathrm{ZHD}=\frac{(2.2768 \pm 0.0005) P_{s}}{f(\phi, H)}$

with ZHD in $\mathrm{mm}$ and $P_{s}$ in $\mathrm{hPa}$. The term

$f(\phi, H)=1-0.00266 \cos 2 \phi-0.00028 H$

accounts for the dependence of gravity acceleration from latitude $\phi$ and surface height above the ellipsoid $H$ (in kilometers). The ratio between IWV and ZWD is given by a conversion factor $\Pi$

$\mathrm{IWV}=\mathrm{ZWD} \cdot \Pi$

which depends on the water vapor weighted atmospheric mean temperature $T_{m}$.

$\Pi^{-1}=10^{-6} \rho_{\mathrm{H}_{2} \mathrm{O}} R_{v}\left(\frac{c_{1}}{T_{m}}+c_{2}\right)$

Here $\rho_{\mathrm{H}_{2} \mathrm{O}}$ denotes the density of liquid water $\left(10^{3} \mathrm{~kg} \mathrm{~m}^{-3}\right)$ and $R_{v}$ the specific gas constant of water vapor $\left(461.5 \mathrm{~J} \mathrm{~kg}^{-1} \mathrm{~K}^{-1}\right.$ ). Following Bevis et al. (1994) the two constants are

$c_{1}=(3.739 \pm 0.012) 10^{5} \mathrm{~K}^{2} \mathrm{hPa}^{-1}$

and

$c_{2}=(22.1 \pm 2.2) \mathrm{KhPa}^{-1}$.

The water vapor weighted mean temperature is defined as

$T_{m}=\frac{\int\left(P_{v} / T\right) d z}{\int\left(P_{v} / T^{2}\right) d z}$

and can be calculated from vertical profiles of water vapor pressure $P_{v}$ and temperature $T$, usually derived from NWP analysis fields (e.g., Wang et al., 2005). Assuming a linear relation with surface temperature it is also possible to approximate $T_{m}$ from station temperature observations $T_{s}$ (Bevis et al., 1992).

$T_{m} \approx 70.2+0.72 T_{s}$ 

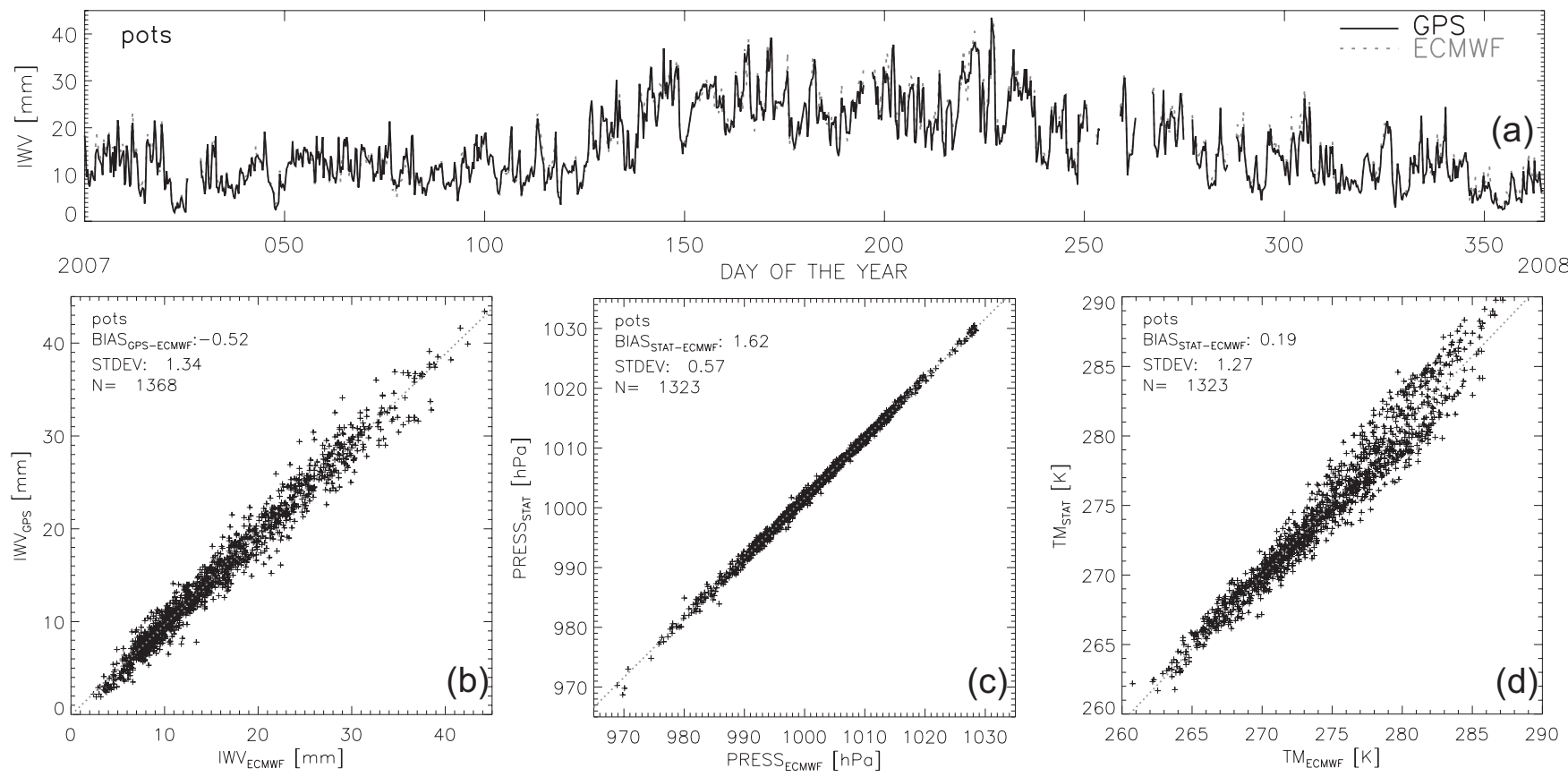

Fig. 1. Results for station Potsdam, year 2007: (a) comparison of IWV from GPS and ECMWF at 00:00, 06:00, 12:00, 18:00 UT (time of ECMWF analyses), (b) scatter plot corresponding to (a), (c) comparison of $P_{S}$ from ECMWF and station sensor at 03:00, 09:00, 15:00, 21:00 UT (worst case estimation), (d) same as (c) but for $T_{m}$.

But this approach suffers from systematic $T_{m}$ overestimation at mid and high latitudes (up to $5 \mathrm{~K}$ ) and underestimation at low latitudes (up to $6 \mathrm{~K}$ ) (Wang et al., 2005). Nevertheless, GPS IWV is rather robust against $T_{m}$ uncertainties. While a $P_{S}$ variation of $1 \mathrm{hPa}$ corresponds to about $0.35 \mathrm{~mm}$ IWV, a $T_{m}$ uncertainty of $5 \mathrm{~K}$ is related to $1.7-2.0 \%$ in IWV (Hagemann et al., 2003). In this study both $P_{s}$ and $T_{m}$ are extracted from ECMWF global analysis fields which provide a horizontal resolution of about $50 \mathrm{~km}$. For horizontal interpolation to station position (according to ZPD file header information) the ECMWF interpolation library (EMOSLIB, www.ecmwf.int) is used. All ECMWF data are linearly interpolated according to time of ZPD observation between the 6-hourly analysis fields. The ECMWF model covers 60 (91 since February 2006) vertical levels from near surface up to $0.1 \mathrm{hPa}$. Applying Eq. (6) $T_{m}$ is calculated as a fraction of two sums according to the ECMWF layers starting from station altitude upwards. Since ECMWF level altitude refers to geoid surface (and geopotential respectively), geoid altitude of the IGS stations is needed for vertical assignment and interpolation of the ECMWF data. Especially the GPS IWV sensitivity to station pressure inaccuracies necessitates accurate station altitudes above geoid surface. In this study ellipsoidal coordinates are calculated from the cartesian IGS station position given in the header section of each ZPD file. In a second step the station geoid altitude is derived using geoid undulation data from the EGM96 geoid model (Lemoine et al., 1998). For vertical interpolation one has to distinguish between two cases: If station altitude is above the lowest ECMWF level temperature and specific humidity (for ECMWF IWV integration) are linearly, and pressure is logarithmically interpolated. If station altitude is below the lowest ECMWF level, temperature is extrapolated using the mean temperature gradient of the three lowest ECMWF layers. Pressure is calculated by stepwise application $(20 \mathrm{~m}$ steps) of the barometric height formula and specific humidity for IWV integration is estimated in parallel, assuming that the mean relative humidity of the two lowest ECMWF levels is representative for the atmosphere below. For subsequent validation ECMWF specific humidity is integrated to IWV according to each GPS IWV observation, starting from station altitude upwards.

Generally all IGS ZPD data can be converted to IWV. However, significant errors in $P_{s}$ and $T_{m}$ estimation may arise if station altitude is far beneath the lowest ECMWF level in mountain regions. Thus, in the following sections only stations with less than $500 \mathrm{~m}$ difference between lowest ECMWF level and station altitude are considered. This concerns about $85 \%$ of all IGS stations.

\section{Selected station results}

In the following we present GPS IWV results of three representatively selected stations from mid latitudes (Potsdam), tropics (Cocos) and polar regions (Davis) for the year 2007. All selected stations are equipped with ground 


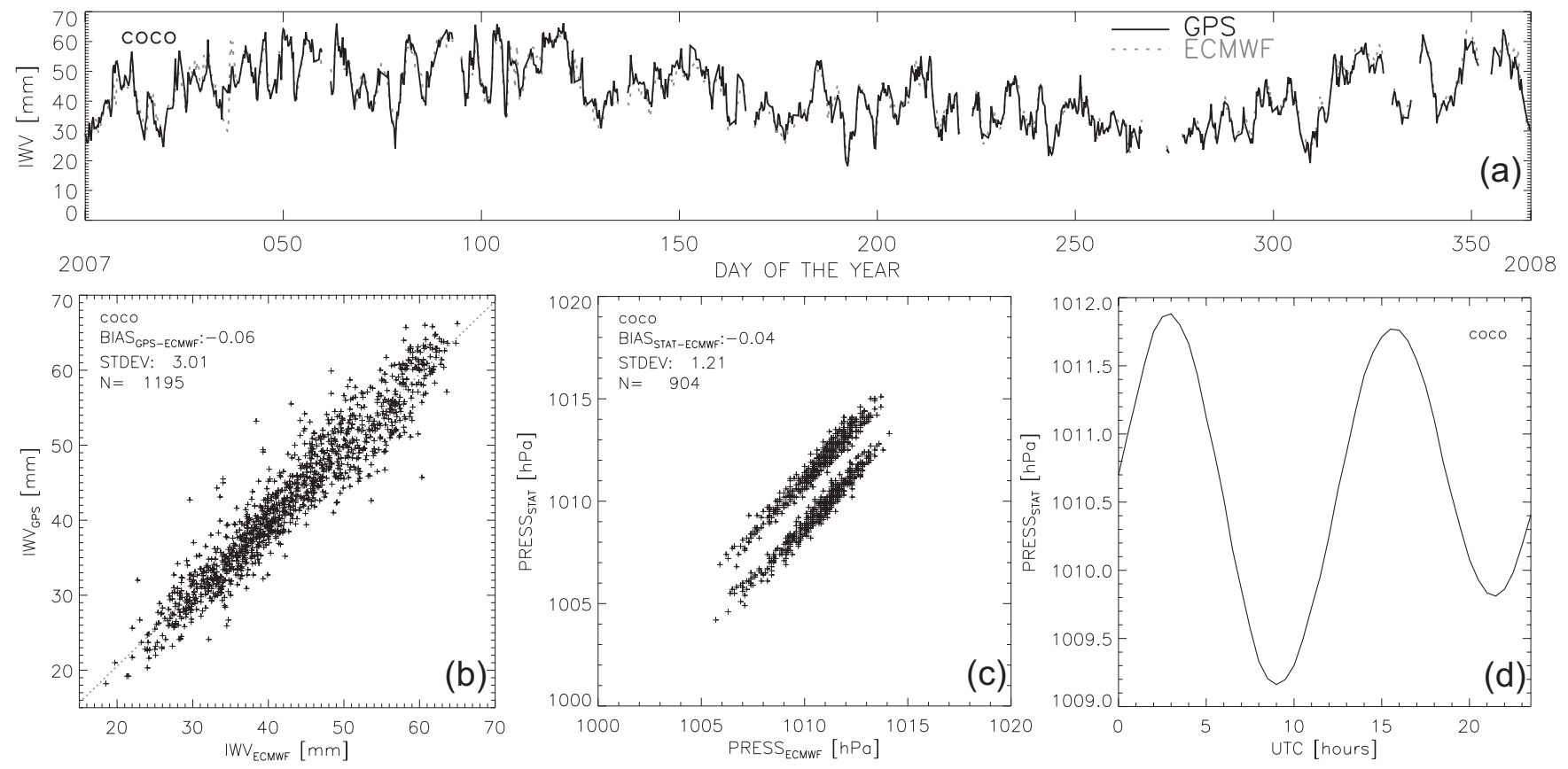

Fig. 2. Results for station Cocos, (a-c) same as Fig. 1. Panel (d) shows ground pressure mean diurnal cycle as derived from ground meteorological data.

meteorological sensors to enable pressure and temperature comparisons between ECMWF and local measurements. Despite the known reliability limitations of the IGS surface meteorological data (e.g., Byun et al., 2005; Wang et al., 2007), these comparisons allow for accuracy estimation of the spatially and temporally interpolated ECMWF data $P_{s}$ and $T_{m}$ used for IWV conversion. To exclude outliers in $P_{S}$ and $T_{S}$ station sensor data from the comparison a rough but from our experience effective threshold ( $10 \mathrm{hPa}$ or $\mathrm{K}$, respectively) concerning the deviation from corresponding ECMWF data was applied. It should be noted that for consistency reasons $T_{m}$ comparisons (Figs. 1 and $3 \mathrm{~d}$ ) refer to mean temperature estimations from both ECMWF and locally measured $T_{s}$ data applying Eq. (7). Due to the already mentioned limitations of this approach, the $T_{m}$ comparisons give only a rough idea on the accuracy of the $T_{m}$ data derived from ECMWF vertical profiles which are actually used for IWV conversion. While GPS and ECMWF IWV (Figs. 1-3 a and b) is compared only at ECMWF analysis times (00:00, 06:00, 12:00, 18:00 UT) to ensure highest ECMWF IWV quality, the $P_{s}$ and $T_{m}$ comparisons between ECMWF and local measurements (Figs. 1 and $3 \mathrm{c}-$ d, Fig. $2 \mathrm{c}$ ) refer only to times between the ECMWF analyses (03:00, 09:00, 15:00, 21:00 UT) for a worst case estimation. Regarding the $P_{s}$ and $T_{m}$ comparisons at ECMWF analysis times (not shown here) this allows for estimation of uncertainties related to temporal interpolation between the 6hourly ECMWF analysis fields.

The 2007 results for Potsdam $\left(52.38^{\circ} \mathrm{N} / 13.07^{\circ} \mathrm{E}\right.$, station altitude $104.2 \mathrm{~m}$, lowest ECMWF level altitude $55.9 \mathrm{~m}$ ) are shown in Fig. 1. Panel (a) reveals the typical seasonal IWV behavior with peak values above $40 \mathrm{~mm}$ in summer and rather dry conditions partly below $5 \mathrm{~mm}$ in winter. GPS IWV agrees well with ECMWF through the entire year indicating high quality of both GPS and ECMWF IWV. The mean deviation (bias) is $-0.52 \mathrm{~mm}$ with a standard deviation of $1.34 \mathrm{~mm}$ (panel b). The $P_{s}$ and $T_{m}$ comparisons (panels c and d) show well agreement between local measurements and interpolated ECMWF data at times between the ECMWF analyses. Standard deviations/biases are $0.57 / 1.62 \mathrm{hPa}$ and $1.27 / 0.19 \mathrm{~K}$ for $P_{s}$ and $T_{m}$, respectively. The rather high pressure bias between ECMWF and local measurements is probably related to deficient pressure sensor calibration (see also Byun et al., 2005). The corresponding comparisons at ECMWF times (not shown) give nearly identical bias values with slightly smaller standard deviations $(0.25 \mathrm{hPa}$ and $0.99 \mathrm{~K})$. Assuming that the temporal interpolation error is independent of the errors in ECMWF and local measurements, the interpolation related standard deviation can be estimated from the difference of the variances observed between and at ECMWF times. Considering the relations between $P_{S}$, $T_{m}$ and IWV variations (section data analysis), the small increase in $P_{S}$ and $T_{m}$ standard deviations corresponds to an interpolation related IWV standard deviation of about $0.2 \mathrm{~mm}$.

Corresponding to Fig. 1 the 2007 IWV results for station Cocos $\left(12.19^{\circ} \mathrm{S} / 96.83^{\circ} \mathrm{E}\right.$, station altitude $4.7 \mathrm{~m}$, lowest ECMWF level altitude $10.8 \mathrm{~m}$ ) are given in Fig. 2 (with exception of panel d). The tropical IWV exhibits humid conditions through the entire year ranging from about 30 up to 

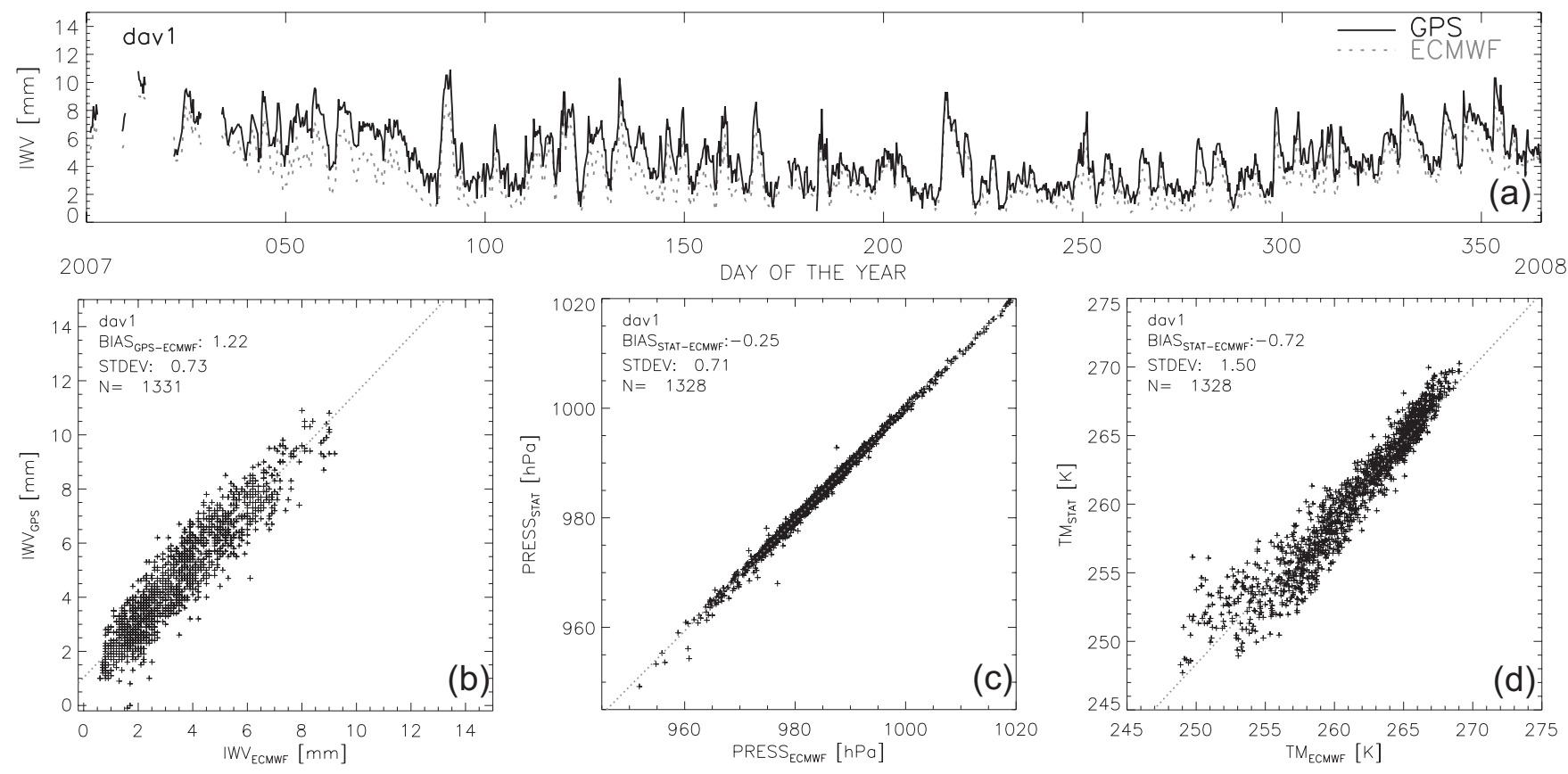

Fig. 3. Same as Fig. 1 but for station Davis.

nearly $70 \mathrm{~mm}$ with a small minimum in southern hemispheric spring. The comparison between GPS and ECMWF IWV shows nearly no bias but a standard deviation of about $3 \mathrm{~mm}$. This is probably related to ZPD inaccuracies resulting from high ionospheric activity (crest region) in low latitudes. But also the horizontal and temporal resolution or assimilated humidity data of the ECMWF analyses may be not sufficient to represent the high IWV variability. Nevertheless, considering the standard deviations with respect to the mean IWV conditions Cocos and Potsdam are about in the same range. In order to determine if the large standard deviation is related to the ionosphere, mean standard deviations between GPS and ECMWF IWV at high (year 2001) and low (2007) solar/ionospheric activity have been calculated. While the global comparison (similar to Fig. 4, not shown here) indicates a mean standard deviation of about $2.5 \mathrm{~mm}$ IWV for 2001, only about $2 \mathrm{~mm}$ are observed for 2007. Considering only equatorial stations, the difference between high and low ionospheric activity is even more pronounced (about $4 \mathrm{~mm}$ and $3.1 \mathrm{~mm}$ IWV standard deviation, respectively). Assuming that the ECMWF IWV precision is independent from solar cycle this indicates ionospheric dependence of the GPS IWV accuracy. The $P_{S}$ comparison (panel c) displays a clear limitation of the temporal pressure interpolation between the 6-hourly ECMWF analysis fields. While there is nearly no bias, a standard deviation of $1.21 \mathrm{hPa}$ is observed in connection with a systematic over- or underestimation of the local measurements by the ECMWF-derived $P_{s}$ data. The corresponding $P_{s}$ comparison at ECMWF times (not shown) gives a significant smaller standard deviation $(0.31 \mathrm{hPa})$ and no sign for systematic over- or underestimation. This effect can easily be explained regarding the mean diurnal pressure behavior at Cocos station (panel d). The well-known double wave structure of the pressure diurnal cycle with maxima in the morning and late evening hours and minima in the afternoon and late night time is mostly pronounced in tropical regions due to the absence of low- and high pressure systems which dominate the pressure diurnal cycle outside the tropics (e.g., the range in the mean diurnal cycle for Potsdam is below $1 \mathrm{hPa}$ ). The local time situation of Cocos makes it impossible to resolve the pressure diurnal cycle from the 6-hourly ECMWF fields resulting in systematic overestimation of the minima and underestimation of the maxima. This should be considered especially in applications of the here presented IWV data set for humidity diurnal cycle investigations.

The 2007 results for Davis $\left(68.58^{\circ} \mathrm{S} / 77.97^{\circ} \mathrm{E}\right.$, station altitude $26.9 \mathrm{~m}$, lowest ECMWF level altitude $69.2 \mathrm{~m}$ ) are given in Fig. 3. Panel (a) shows the well-known dry conditions of the southern polar region with IWV values below $10 \mathrm{~mm}$ nearly throughout the whole year and a minimum in southern hemispheric winter. It is interesting to note that there is well agreement between ECMWF and GPS IWV in winter while ECMWF is significantly lower than GPS especially in autumn but also in spring and summer. A similar behavior of the GPS-ECMWF IWV difference is also observed for the other antarctic stations. This gives some evidence that except for the winter season ECMWF undervalues humidity in the southern polar region, mostly pronounced in autumn (see also Fig. 5 for mean bias). As Fig. 3b shows, 

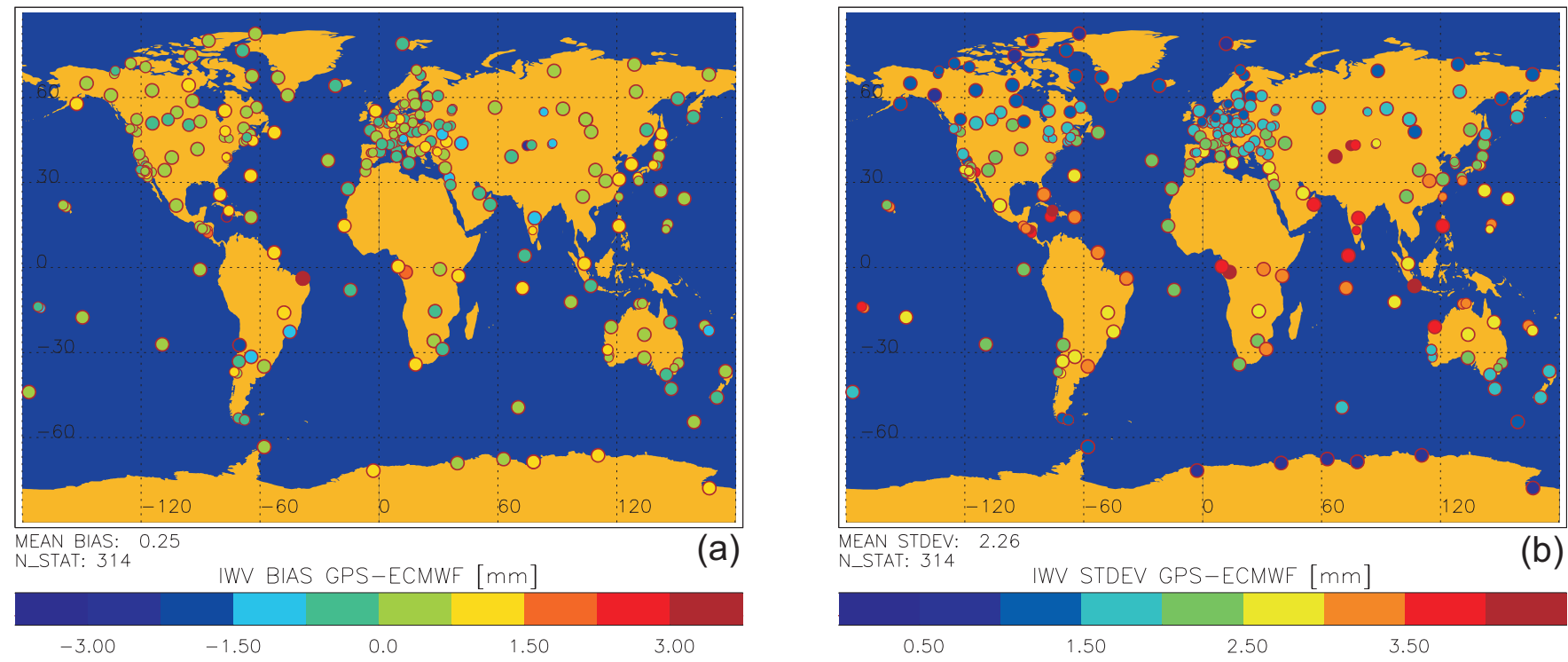

Fig. 4. GPS IWV results 2000-2007 from stations with more than one year of data in comparison with IWV from ECMWF at 00:00, 06:00, 12:00, 18:00 UT (time of ECMWF analyses): (a) bias, (b) standard deviation. Size of station symbols depends on distance from neighbouring stations.

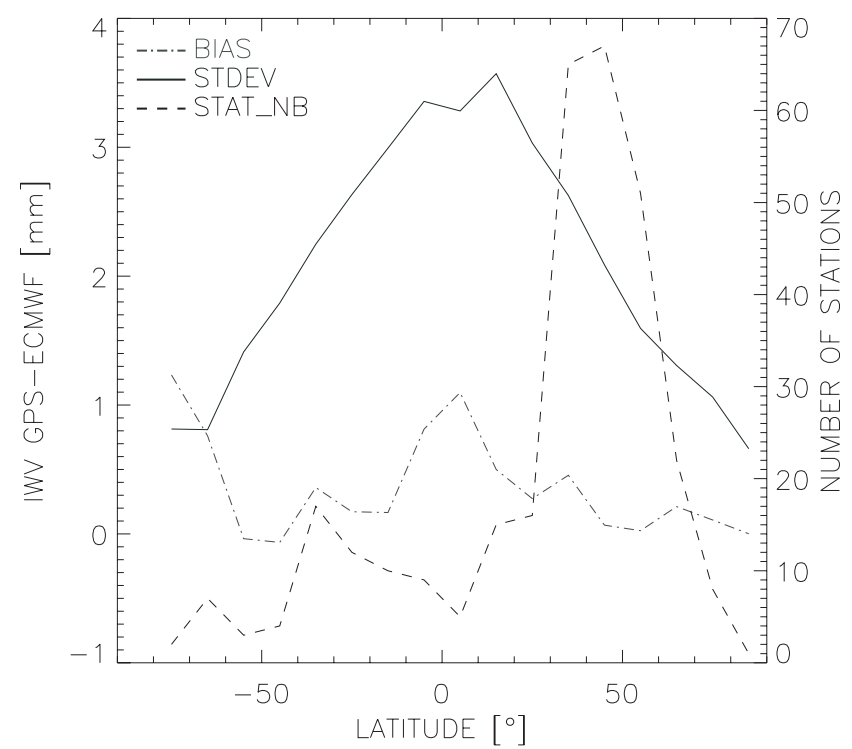

Fig. 5. Latitudinal dependence of IGS station number (dashed line), zonal mean bias (dash dot line) and standard deviation (solid line) between GPS and ECMWF IWV corresponding to Fig. 4. Zonal means and station number refer to $10^{\circ}$ latitude bins.

the comparison between GPS and ECMWF IWV gives about $1.22 \mathrm{~mm}$ bias and $0.73 \mathrm{~mm}$ standard deviation. The $P_{S}$ and $T_{m}$ comparisons (panels $\mathrm{c}$ and d) show good agreement between local measurements and interpolated ECMWF data at times between the ECMWF analyses. Standard deviations/biases are $0.71 /-0.25 \mathrm{hPa}$ and $1.5 /-0.72 \mathrm{~K}$, respectively. While corresponding comparisons at ECMWF times (not shown) give nearly the same $T_{m}$ standard deviation and bias $(1.46 /-0.69 \mathrm{~K})$, the $P_{S}$ standard deviation is slightly smaller $(0.57 \mathrm{hPa}$, bias $-0.24 \mathrm{hPa})$. The small increase in $P_{S}$ standard deviation corresponds to an interpolation related IWV standard deviation of about $0.15 \mathrm{~mm}$. In this context the range of the pressure mean diurnal cycle for Davis (not shown) is only about $0.2 \mathrm{hPa}$.

\section{Overall comparisons}

In this section a general view on the GPS IWV results in comparison to ECMWF is given. Furthermore, $P_{s}$ and $T_{m}$ comparisons between local measurements and interpolated ECMWF data are presented for all accordingly equipped stations. Similar to the single station results in previous section IWV (Figs. 4 and 5) is compared only at ECMWF analysis times to ensure highest ECMWF IWV quality while $P_{S}$ and $T_{m}$ comparisons (Figs. 6 and 7) refer to times between the ECMWF analyses to estimate maximum standard deviations. Also the outlier criterion for local $P_{S}$ and $T_{S}$ measurements (maximum deviation form interpolated ECMWF data of $10 \mathrm{hPa}$ or $\mathrm{K}$, respectively) is applied.

The comparisons shown in Figs. 4 and 5 refer to IWV results from 2000 until 2007 for all stations with at least one year of data within this period. The maximum altitude difference of $500 \mathrm{~m}$ between station and according lowest ECMWF level selects here 314 of in total 363 stations. Figure 4a reveals low GPS-ECMWF IWV biases for most of the stations. The overall mean bias is $0.25 \mathrm{~mm}$. In fact 43 stations exceed a bias of $\pm 1 \mathrm{~mm}$ and only three stations (CHUM, FORT, JAMA) exceed $\pm 2 \mathrm{~mm}$. The maximum bias 

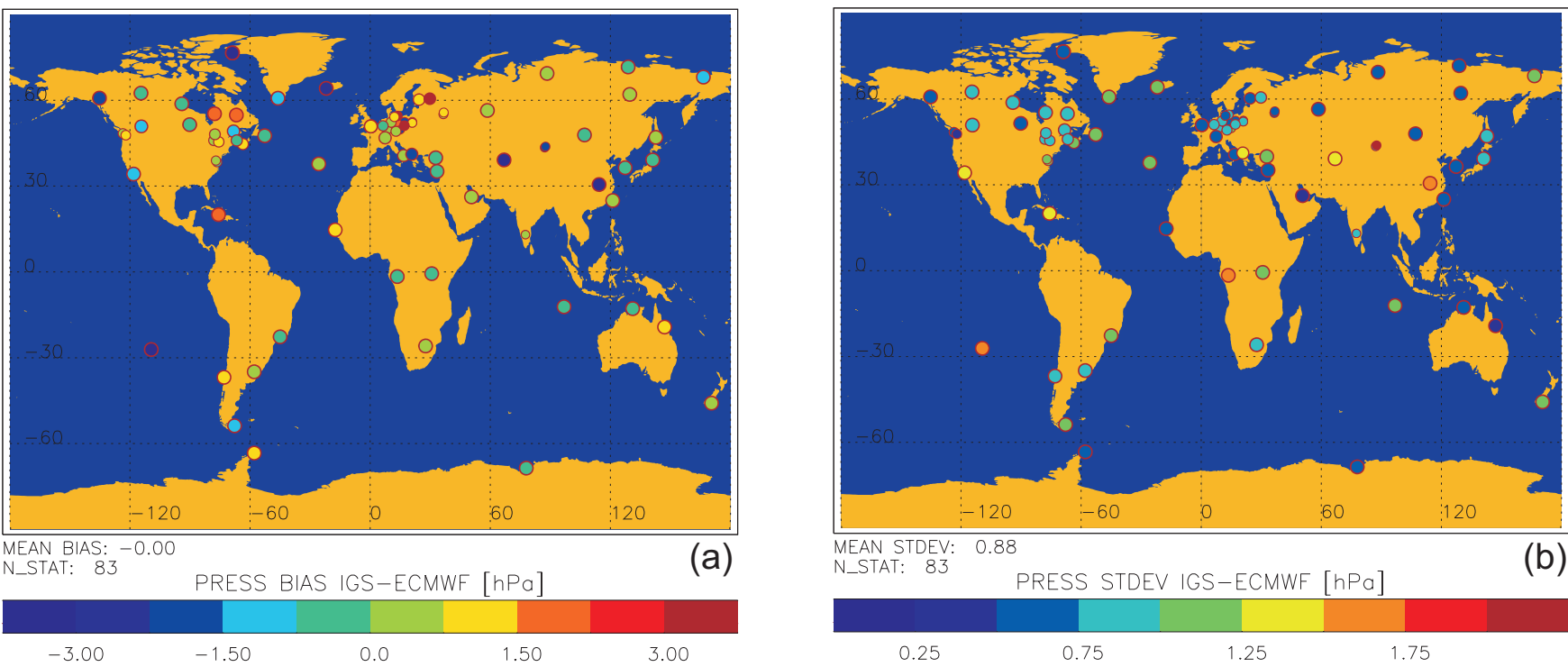

Fig. 6. Comparison of $2007 P_{S}$ data from ECMWF and station sensors at 03:00, 09:00, 15:00, 21:00 UT: (a) bias, (b) standard deviation.
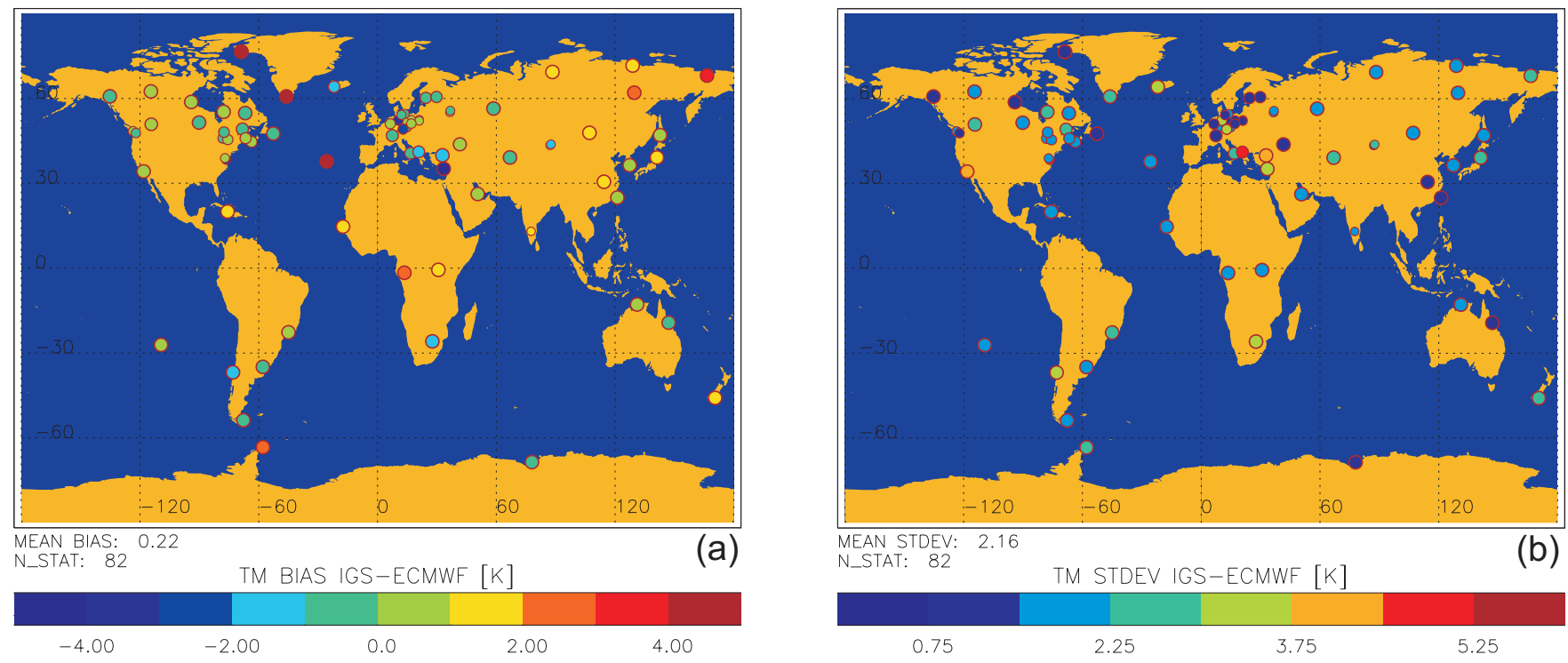

Fig. 7. Same as Fig. 6 but for mean temperature $T_{m}$.

of $3.12 \mathrm{~mm}$ is observed for the tropical station FORT. This is in the range reported by Hagemann et al. (2003) for some suspicious stations. Figure 5 reveals hemispheric symmetry of the mean zonal bias for mid and low latitudes with a maximum near the equator. As already discussed in previous section, a mean bias of about $1.2 \mathrm{~mm}$ is observed for the southern polar region. It is generally difficult to identify whether the IWV bias is related to ECMWF or GPS (including $\mathrm{ZPD}, P_{s}$ and $T_{m}$ data). However, the altitude difference between lowest ECMWF level and GPS antenna is below $200 \mathrm{~m}$ for the three mentioned stations making a problem in vertical pressure or humidity extrapolation improba- ble. The standard deviations shown in Fig. 4b also reveal well agreement between GPS and ECMWF IWV for most of the stations especially in mid and high latitudes. However, tropical stations generally exhibit higher standard deviations. The latitudinal dependence of the standard deviation is also clearly visible in Fig. 5. As already mentioned for Cocos station this is probably related to the ionospheric active regions around the equator but may also result from limitations of the ECMWF analyses to represent the high spatial and temporal IWV variability in humid regions. The overall mean standard deviation is $2.26 \mathrm{~mm}$ where most of the midlatitude stations are around $1.5 \mathrm{~mm}$ and high latitude stations below 
$1 \mathrm{~mm}$ (Fig. 5). A standard deviation of more than $4 \mathrm{~mm}$ is observed for six stations with a maximum of $4.36 \mathrm{~mm}$ for the Indonesian station BAKO. Also here deficiencies in vertical pressure or humidity extrapolation are unlikely since five of these stations show an altitude difference of less than $200 \mathrm{~m}$ between lowest ECMWF level and GPS antenna. In general the observed GPS-ECMWF IWV standard deviation is consistent with previous GPS IWV validation studies (less than $3 \mathrm{~mm}$ ) (e.g., Li et al., 2003; Hagemann et al., 2003; Deblonde et al., 2005; Wang et al., 2007).

The $P_{s}$ comparisons between local measurements at 83 stations and interpolated ECMWF (at 03:00, 09:00, 15:00, 21:00 UT) data are shown in Fig. 6. Since we observed significant quality improvement (primary reduced standard deviations with respect to ECMWF) of IGS pressure data for several (especially Canadian) stations in 2006, these comparisons are confined to 2007 data. Figure 6 reveals well $P_{S}$ agreement for numerous stations. While the overall mean bias (panel a) is zero there are 12 stations exceeding $\pm 2 \mathrm{hPa}$. The maximum bias $(7.4 \mathrm{hPa})$ probably related to missing ground sensor calibration is observed for station SVTL. Nevertheless, the results of a similar surface pressure comparison by Hagemann et al. (2003) for about 40 IGS stations in 2000/2001 (where most of the stations showed biases of more than $3 \mathrm{hPa}$ ) can not be confirmed. Considering the already mentioned reliability limitations of IGS surface meteorological data (especially regarding calibration) we find from the bias results no general impropriety of ECMWF $P_{s}$ data for ZPD to IWV conversion. The overall mean standard deviation between ECMWF and locally measured $P_{s}$ is $0.88 \mathrm{hPa}$ (panel b) while corresponding comparisons at ECMWF times (not shown) give an slightly smaller value of $0.75 \mathrm{hPa}$ (and the same mean bias). The small increase in $P_{S}$ mean standard deviation corresponds to a temporal interpolation related IWV standard deviation of about $0.16 \mathrm{~mm}$. Thus, for most of the stations the IWV uncertainty related with temporal interpolation of ECMWF pressure data is negligible small in comparison to the expectable IWV accuracy (standard deviations from validation studies). However, the maximum interpolation related increase in $P_{S}$ standard deviation is nearly $1 \mathrm{hPa}$ for the tropical station MSKU. The reason for this large interpolation error has already been discussed in previous section for station Cocos. MSKU $\left(13.55^{\circ} \mathrm{E}\right)$ shows nearly the same local time situation with respect to the ECMWF analysis times and the ground pressure diurnal cycle (even though derived from only 12 days of applicable data in 2007) is also similar but even more pronounced than for Cocos. It should also be noted that the average standard deviation between $P_{s}$ from ECMWF and local meteorological data is well below the $1.65 \mathrm{hPa}$ RMS difference reported by Wang et al. (2007) for comparison of $P_{S}$ interpolated from nearby surface synoptic observations with local measurements at 48 GPS sites. This indicates that $P_{s}$ derivation from nearby synoptic stations is in general not superior to the application of ECMWF analysis data.
The $T_{m}$ comparisons corresponding to Fig. 6 for $P_{s}$ are shown in Fig. 7. As already mentioned in previous section for consistency reasons Fig. 7 refers to mean temperature estimations from both ECMWF and locally measured $T_{s}$ data applying Eq. (7). As seen from panel (a) most of the 82 stations show no significant bias between local measurement and ECMWF, the overall mean bias is $0.22 \mathrm{~K}$. Only 8 stations exceed a bias of $\pm 3 \mathrm{~K}$, the maximum bias is observed for station THU3 (Greenland) with $8.25 \mathrm{~K}$. Figure $7 \mathrm{~b}$ reveals an overall mean standard deviation of $2.16 \mathrm{~K}, 10$ stations exceed $3 \mathrm{~K}$ here. The maximum standard deviation is found for station ORID $(5.22 \mathrm{~K})$. The $T_{m}$ comparisons at ECMWF times (not shown) come to nearly the same mean bias $(0.16 \mathrm{~K})$ and standard deviation $(2.21 \mathrm{~K})$. Also the maximum temporal interpolation related increase in $T_{m}$ standard deviation is only $0.66 \mathrm{~K}$ (station KIT3). From these results IWV uncertainty related with temporal interpolation of ECMWF temperature data appears negligible.

\section{Conclusions}

Global ECMWF analysis data have been applied to convert the 5-min IGS ZPD dataset to IWV. A comparison of IWV from GPS and ECMWF shows well agreement for most GPS stations. Larger discrepancies in this comparison can easily be used to identify suspicious stations in GPS IWV data. Such significant deviations especially occur in mountain regions due to altitude extrapolation errors but can also be related to errors in station altitude or insufficient horizontal model resolution in presence of climate or weather boundaries. The comparison of measurements from IGS station surface meteorology sensors with corresponding ECMWFderived data indicates reasonable agreement for most stations. In order to apply station meteorology data for a reliable IWV conversion, ECMWF data can effectively be used to identify outliers in these local measurements. The uncertainty in GPS IWV related with temporal interpolation between the 6-hourly ECMWF analysis fields has been estimated by comparison of ECMWF-derived data with station sensor measurements at times of ECMWF analyses and three hours displaced from these times. Considering the increase in pressure and mean temperature standard deviations, the mean uncertainty introduced by time interpolation is estimated below $0.2 \mathrm{~mm}$. Nevertheless, temporal station pressure interpolation may result in up to $0.5 \mathrm{~mm}$ IWV uncertainty (in terms of standard deviation) if a pronounced ground pressure diurnal cycle is present (especially observed in the tropics) and the ECMWF analyses do not represent this cycle due to local time situation of the station.

Acknowledgements. The authors are grateful to the IGS community for maintenance of the global network and data provision. The German Weather Service provided ECMWF analysis data.

Topical Editor F. D’Andrea thanks S. Byun and T. Nilsson for their help in evaluating this paper. 


\section{References}

Beutler, G., Rothacher, M., Schaer, S., Springer, T. A., Kouba, J., and Neilan, R. E.: The International GPS Service (IGS): An interdisciplinary service in support of earth sciences, Adv. Space Res., 23, 631-635, 1999.

Bevis, M., Businger, S., Herring, T. A., Rocken, C., Anthes, R. A., and Ware, R. H.: GPS meteorology: Remote sensing of atmospheric water vapour using the Global Positioning System, J. Geophys. Res., 97(D14), 15787-15801, 1992.

Bevis, M., Businger, S., Chiswell, S., Herring, T. A., Anthes, R. A., Rocken, C., and Ware, R. H.: GPS meteorology: Mapping zenith wet delays onto precipitable water, J. Appl. Meteorol., 33, 379-386, 1994.

Businger, S., Chiswell, S. R., Bevis, M., Duan, J., Anthes, R. A., Rocken, C., Ware, R. H., Exner, M., Van Hove, T., and Solheim, F.: The promise of GPS in atmospheric monitoring, B. Am. Meteorol. Soc., 77, 5-18, 1996.

Byun, S. H., Bar-Server, Y. E., and Gendt, G.: The new tropospheric product of the International GNSS Service, proceedings of ION GNSS 18th International Technical Meeting of the Satellite Division, 2005.

Davis, J. L., Herring, T. A., Shapiro, I. I., Rogers, A. E. E., and Elgered, G.: Geodesy by radio interferometry: Effects of atmospheric modelling errors on estimates of baseline length, Radio Sci., 20, 6, 1593-1607, 1985.

Deblonde, G., Macpherson, S., Mireault, Y., and Héroux, P.: Evaluation of GPS precipitable water over Canada and the IGS network, J. Appl. Meteorol., 44, 153-166, 2005.

Gendt, G., Dick, G., Reigber, C., Tomassini, M., Liu, Y., and Ramatschi, M.: Near real time GPS water vapor monitoring for numerical weather prediction in Germany, J. Meteorol. Soc. Jpn, 82, 361-370, 2004.

Gradinarsky, L. P., Johansson, J. M., Bouma, H. R., Scherneck, H. G., and Elgered, G.: Climate monitoring using GPS, Phys. Chem. Earth, 27, 335-340, 2002.

Guerova, G., Bettems, J.-M., Brockmann, E., and Matzler, C.: Assimilation of COST 716 Near-Real Time GPS data in the nonhydrostatic limited area model used at MeteoSwiss, Meteor. Atmos. Phys., 91, 149-164, 2006.

Gutman, S. I., Sahm, S. R., Benjamin, S. G., Schwartz, B. E., Holub, K. L., Stewart, J. Q., and Smith, T. L.: Rapid retrieval and assimilation of ground based GPS precipitable water observations at the NOAA forecast systems laboratory: Impact on weather forecasts, J. Meteorol. Soc. Jpn, 82, 351-360, 2004.

Hall, A. and Manabe, S.: The role of water vapor feedback in unperturbed climate variability and global warming, J. Climate, 12, 2327-2346, 1999.
Hagemann S., Bengtsson, L., Gendt, G.: On the determination of atmospheric water vapor from GPS measurements, J. Geophys. Res., 108(D21), 4678, doi:10.1029/2002JD003235, 2003.

McCarthy, D. D. and Petit, G. (Eds.), IERS Conventions, Technical Note 32, Frankfurt am Main, Verlag des Bundesamts für Kartographie und Geodäsie, ISBN 3-89888-884-3, 2003.

Lemoine, F. G., Kenyon, S. C., Factor, J. K., Trimmer, R.G., Pavlis, N. K., Chinn, D. S., Cox, C. M., Klosko, S. M., Luthcke, S. B., Torrence, M. H., Wang, Y. M., Williamson, R. G., Pavlis, E. C., Rapp, R. H., and Olson, T. R.: The Development of the Joint NASA GSFC and NIMA Geopotential Model EGM96, NASA Goddard Space Flight Center, Greenbelt, Maryland, USA, 1998.

Li, Z., Muller, J.-P., and Cross, P.: Comparison of precipitable water vapor derived from radiosonde, GPS, and Moderate-Resolution Imaging Spectroradiometer measurements, J. Geophys. Res., 108(D20), 4651, doi:10.1029/2003JD003372, 2003.

Nilsson T. and Elgered, G.: Long-term trends in the atmospheric water vapor content estimated from ground-based GPS data, J. Geophys. Res., 113, D19101, doi:10.1029/2008JD010110, 2008.

Rocken, C., Ware, R. H., Van Hove, T., Solheim, F., Alber, C., and Johnson, J.: Sensing atmospheric water vapor with the Global Positioning System, Geophys. Res. Lett., 20, 2631-2634, 1993.

Saastamoinen, J.: Atmospheric correction for the troposphere and stratosphere in radio ranging of satellites, The use of artificial satellites for geodesy, Geophysical Monograph Series, 15, edited by: Henriksen, S. W., Mancini, A., and Chovitz B. H., AGU CODE GM0150151, 247-251, 1972.

Tregoning, P., Boers, R., O'Brien, D., and Hendy, M.: Accuracy of absolute precipitable water vapor estimates from GPS observations, J. Geophys. Res., 103(D22), 28701-28710, 1998.

Van Baelen, J., Aubagnac, J.-P., and Dabas, A.: Comparison of nearreal time estimates of integrated water vapor derived with GPS, radiosondes, and microwave radiometer, Journal of Atmospheric and Oceanic Technology, 22(2), 201-210, doi:10.1175/JTECH-1697.1, 2005.

Vedel, H., Huang, X.-Y., Haase, J., Ge, M., and Calais, E.: Impact of GPS zenith tropospheric delay data on precipitation forecasts in Mediterranean France and Spain, Geophys. Res. Lett., 31, L02102, doi:10.1029/2003GL017715, 2004.

Wang, J., Zhang, L., and Dai, A.: Global estimates of water-vapor-weighted mean temperature of the atmosphere for GPS applications, J. Geophys. Res., 110, D21101, doi:10.1029/2005JD006215, 2005.

Wang, J., Zhang, L., Dai, A., Van Hove, T., and Van Baelen, J.: A near-global, 2-hourly data set of atmospheric precipitable water from ground-based GPS measurements, J. Geophys. Res., 112, D11107, doi:10.1029/2006JD007529, 2007.

Zhai, P. and Eskridge, R. E.: Analyses of inhomogeneities in radiosonde temperature and humidity time series, J. Climate, 9, 884-894, 1996. 